\title{
AS ABORDAGENS EPISTEMOLÓGICAS, TEÓRICAS E METODOLÓGICAS UTILIZADAS NOS ESTUDOS DA CULTURA ORGANIZACIONAL
}

Letícia Rodrigues da FONSECA ${ }^{1}$

Marcelo Ribeiro SILVA ${ }^{2}$

Sheldon William SILVA ${ }^{3}$

Guilherme Marques PEREIRA ${ }^{4}$

\begin{abstract}
${ }^{1}$ Doutora em Administração pela Universidade Presbiteriana (UPM). Professora na Universidade Vale do Rio Verde (UNINCOR). leticia.rodrigues.vga@gmail.com

${ }^{2}$ Doutor em Administração pela Universidade Presbiteriana Mackenzie (UPM). Professor na Universidade Federal do Mato Grosso do Sul (UFMS).

${ }^{3}$ Mestre em Administração pela Faculdade Pedro Leopoldo. Professor no Centro Universitário do Sul de Minas.

${ }^{4}$ Mestre em Administração pela Campanha Nacional de Escolas da Comunidade (CNEC). Professor na Faculdade Cenecista de Varginha (FACECA).
\end{abstract}

Recebido em: 03/01/2017 - Aprovado em: 30/06/2017 - Disponibilizado em: 01/07/2017

\begin{abstract}
RESUMO
O presente estudo visa analisar as especificidades das diferentes abordagens epistemológicas, teóricas e metodologias utilizadas nos estudos da cultura organizacional, bem como os seus propósitos no que se refere a contribuições para o campo de pesquisa. Quanto às abordagens epistemológicas, o paradigma positivista é utilizado quando a cultura é vista como algo que a organização possui; e o interpretativista quando a cultura é vista como algo que a organização é. Quanto às abordagens teóricas, diferentes manifestações culturais são enfatizadas. No entanto, algumas pressuposições sobre a cultura organizacional estão presentes nas visões dos diferentes teóricos. A abordagem metodológica estará relacionada com a perspectiva epistemológica do pesquisador, bem como os elementos culturais que serão investigados. O positivista/objetivista prega o uso de métodos quantitativos e o subjetivista/interpretativista propõe o uso de métodos qualitativos. Ao final do estudo identificou-se a necessidade de reconhecer a complementaridade das diferentes abordagens epistemológicas e metodológicas, visto que ambas oferecem contribuições para uma maior compreensão e elucidação dos diferentes elementos da cultura.
\end{abstract}

Palavras-chave: Cultura Organizacional; Abordagens Epistemológicas; Abordagens Teóricas; Abordagens Metodológicas.

\section{THE EPISTEMOLOGICAL, THEORETICAL AND METHODOLOGICAL APPROACHES APPLIED IN THE STUDIES OF ORGANIZATIONAL CULTURE}

\begin{abstract}
The present study aims to analyze the specificities of the different epistemological, theoretical and methodological approaches applied in organizational culture studies, as well as their contributions to the field of research. As for the epistemological approaches, the positivist paradigm is used when the culture is seen as something that the organization owns; and the interpretative one when the culture is seen as something that the organization is. As for the theoretical approaches, different cultural manifestations are emphasized. However, some assumptions about organizational culture are present in the views of different theorists. The methodological approach will be related to the epistemological perspective of the researcher, as well as the cultural elements that will be investigated. The positivist / objectivist preach the use of quantitative methods and the subjectivist / interpretivist proposes the use of qualitative methods. At the end of the study the necessity to recognize the complementarity of the different epistemological and methodological approaches was identified, since both offer contributions for a greater understanding and elucidation of the different elements of the culture.
\end{abstract}

Keywords: Organizational Culture; Epistemological Approaches; Theoretical Approaches; Methodological Approaches. 


\section{INTRODUÇÃO}

O termo cultura organizacional não é algo recente. Segundo Pépin (1998), o primeiro pesquisador a utilizar o termo cultura para descrever uma organização foi Elliot Jaques em seus estudos, na Inglaterra, em 1951. Após ter desaparecido quase que por completo das pesquisas organizacionais, $\mathrm{o}$ termo cultura corporativa voltou a ser discutido nos trabalhos de Pettigrew em 1979.

De acordo com Reichers e Schneider (1990), a teoria e pesquisa em cultura organizacional tem sido objeto de uma multiplicidade de abordagens teóricas e metodológicas, que ora se assemelham ou se complementam ou ora se excluem mutuamente. Esse campo de conhecimento, embora vasto e promissor ressente-se ainda de maturidade, integração teórica e consistência empírica.

Para Trompenaars (1996), as diferenças culturais podem prejudicar a administração e os negócios em razão das potenciais situações de conflito. Assim sendo, acredita-se que o estudo sobre a cultura organizacional é essencial, no momento em que este oferece subsídios ao gestor para o entendimento da cultura ou "culturas" presentes na empresa (a forma de agir e pensar de seus colaboradores), visando à efetividade organizacional.

Portanto, diante desse cenário, o presente estudo visa discutir algumas das abordagens epistemológicas, teóricas e metodológicas utilizadas nos estudos da cultura corporativa, com o intuito de identificar suas especificidades e seus propósitos no que se refere a oferecer contribuições para este campo de pesquisa.

Para isso, será realizado um estudo teórico que se baseará em obras de alguns dos principais estudiosos sobre cultura organizacional, bem como em obras de autores que tratam sobre as diferentes abordagens epistemológicas e metodológicas utilizadas nos estudos organizacionais.

\section{REFERENCIAL TEÓRICO}

\subsection{As Abordagens Epistemológicas Utilizadas nos Estudos da Cultura Organizacional}

Em se tratando de ciências sociais, quanto à base epistemológica, temos os seguintes paradigmas de abordagem metodológica empírica: o positivismo e interpretacionismo.

$\mathrm{Na}$ pesquisa científica a perspectiva ainda é a positivista que, segundo Remenyi et al. (1998), implica na pesquisa com base em uma realidade social observável cujo produto pode ser derivado de leis produzidas pelas ciências físicas e naturais.

Para Denzi e Lincoln (2003), a visão recebida da ciência (positivismo transformado no decorrer deste século em pós-positivismo) foca em esforços para se verificar ou falsificar 
a priori hipóteses, mais utilmente afirmadas como proposições matemáticas (quantitativas) ou proposições que podem ser facilmente convertidas em fórmulas matemáticas precisas, expressando relacionamentos funcionais.

Segundo Donaldson (2003), o Positivismo ganha muito da sua força em Ciência Organizacional sendo teoricamente derivado do Funcionalismo.

Contudo, o funcionalismo, de acordo com Silverman (1968), na sociologia atraiu muita critica, mas muito desta crítica é sem fundamento, problemas filosóficos são vistos por alguns como sendo inerentes do funcionalismo na ciência social. Para Elster (1983), uma explicação funcionalista pode ser explicada como sendo teleologia sem um sujeito conhecedor. Em termos filosóficos não há alegação ontológica sendo feita, nem há a presunção sobre ontologia sendo feita que é algum tipo de pressuposição na qual a validade da teoria positivista persiste ou cai. As causas situacionais externas usadas em teorias positivistas são construções, como em qualquer teoria.

O positivismo na ciência organizacional busca criar teorias gerais sobre organizações e seus membros, que são remanescentes das poderosas leis universais encontradas nas ciências naturais. A meta é revelar regularidades causais que estão abaixo da superfície da realidade. As explicações são primariamente causas que determinam efeitos.
O perfil do gestor organizacional exerce forte influência em sua preferência pelo paradigma positivista. Segundo Donaldson (2003), a maioria das mudanças organizacionais ocorre por causa das decisões administrativas, assim, idéias nas mentes dos atores sociais são parte do processo que produz as mudanças. Os tomadores de decisão podem considerar uma gama de opções e então escolher entre elas. Blau (1972) apud Donaldson (2003) afirma, que os tomadores de decisão irão escolher a opção mais efetiva, dado que somente uma opção é a mais efetiva. Deste modo, o positivismo ganha força quando unido ao funcionalismo, para que a opção que for escolhida tenha que ser escolhida por causa de sua funcionalidade, isto é, com respeito ao seu desfecho benéfico. Para Cavedon (2002), o funcionalismo permite eliminar uma parte da incerteza quanto às consequiências da ação.

$\mathrm{Na}$ perspectiva interpretacionista, de acordo com Morgan e Smircich (1980), a epistemologia, à luz do enfoque subjetivo, enfatiza a importância da compreensão dos processos pelos quais o homem constrói a realidade e, para tanto, torna-se necessário reconstruir o fenômeno estudado a partir da interpretação dos significados atribuídos pelos agentes envolvidos. No momento em que a pesquisa positivista tem como enfoque a redução de um fenômeno a dimensões quantitativas aderentes a leis e princípios, a perspectiva interpretacionista demanda do 
pesquisador uma descrição interpretativa do fenômeno. $\mathrm{O}$ pesquisador elabora uma imagem holística e complexa, analisa textos, coleta visões detalhadas dos sujeitos de pesquisa e conduz um estudo com "atitude natural".

Segundo Donaldson (2007), no início dos estudos organizacionais, vários pesquisadores atribuíram diversas abordagens sobre as questões relacionadas a significado e interpretação. Como exemplo, podemos citar Weber, que foi um dos poucos pesquisadores que conseguiu desenvolver opiniões sobre a filosofia interpretativa, utilizando estas idéias, inclusive, no que se refere a definições organizacionais. Outros autores também contribuíram com esta abordagem como Roethlisberger e Dickson (1939), que descobriram como uma comunidade de trabalhadores desafiava o conhecimento aceito sobre as leis do comportamento humano. Barnard (1938/1968), pesquisou o papel da comunicação simbólica em sistemas coordenados de ação. Selznick (1949), analisou como a interpretação das pessoas promovia o significado e significância para as organizações e para seus líderes. Boulding (1956), descreveu as organizações como sendo símbolos de transformação dos sistemas sociais.

Ainda, conforme Donaldson (2007), os estudos sobre a perspectiva interpretativa continuaram, no entanto, sua maturidade ocorreu entre os anos de 1980 e 1990, passando a ser considerada relevante na sociologia industrial e a configuração simbólica começou a predominar no campo de estudo. O estudo da cultura organizacional foi antecipado e com isso surgiram os métodos qualitativos de pesquisa denominados teorias de base (1981, 1983). Surgiram ainda, o conceito de culturas de segurança $(1976,1978)$ e as noções sobre simbolismo organizacional.

De acordo com Alvesson (2002), a variedade de abordagens utilizadas nos estudos sobre cultura organizacional é resultante das pressuposições filosóficas e metateóricas que as orientam, ou seja, a distinção entre a visão objetivista/funcionalista e a visão subjetivista/interpretativa da realidade social.

A visão objetivista/funcionalista faz uso de procedimentos nomotéticos sob uma perspectiva ética, determinando significados a um conjunto de dados. Já, a visão subjetivista/interpretativa adota uma perspectiva êmica, na qual cada cultura é única e singular, e o seu significado surge por meio das relações simbólicas e dos significados atribuídos a estas pelos membros do grupo em estudo.

$$
\text { Smircich (1983) apud Alvesson }
$$
(2002), faz uma distinção de cultura, definindo-a como algo que a organização possui e como algo que a organização é. Isso significa visualizar a cultura ou como uma variável ou como uma metáfora. A cultura 
como variável está associada a uma perspectiva tradicional, objetivista e positivista. Os seguidores desta abordagem acreditam que a organização produz traços culturais mais ou menos distintos como valores, rituais, linguagens que afetam o comportamento das pessoas. Acreditam que a cultura dá um senso de identidade aos colaboradores, o que proporciona estabilidade para o sistema, além de atuar como um sistema de orientação e modelagem de comportamento. Os seguidores da segunda abordagem, adotam uma perspectiva fenomenológica, visualizando a organização como se ela fosse a cultura, se fundamentando na antropologia para desenvolver teorias e paradigmas radicais novos.

Desta forma, as organizações seriam constituídas por meio de manifestações que expressam a consciência humana, portanto, devem ser estudadas através de seus aspectos expressivos, ideacionais e simbólicos que unificam as pessoas e tornam as ações partilhadas. Nesta visão os aspectos econômicos, materiais que levam a resultados, produtividade e eficácia organizacional são negligenciadas, pois são vistos como última análise.

\subsection{Abordagens Teóricas nos Estudos da} Cultura Organizacional

De acordo com Vieira e Caldas (2006), uma teoria é composta por um conjunto de hipóteses ou de argumentos utilizados para compreender fenômenos reais. Portanto, uma teoria visa a descrever como as coisas são ou como a realidade é. Uma teoria, para ser considerada científica, deve, ainda, ser capaz de produzir diagnósticos, ou seja, de dizer o que está para acontecer se as condições precedentes forem satisfeitas. Uma teoria é corroborada ou refutada quanto os prognósticos baseados nas suas hipóteses se confirmaram ou não.

Para Reichers e Schneider (1990), os estudos sobre cultura organizacional fazem uso de uma multiplicidade de abordagens teóricas e metodológicas, que ora se assemelham ou se complementam ou ora se excluem mutuamente.

$\mathrm{O}$ introdutor do termo cultura na psicologia organizacional Pettigrew (1979) apud Freitas (1991), a define como um sistema de significados aceitos publicamente e coletivamente por um dado grupo por um dado tempo. Esses sistemas de termos, formas, categorias e imagens, interpretam para as pessoas as suas próprias situações.

Para Schein (1992), um dos autores mais citados nos estudos sobre cultura organizacional, cultura seria um modelo de pressupostos básicos que um dado grupo inventou, descobriu ou desenvolveu aprendendo a lidar com problemas de adaptação externa e integração interna que, suficientemente bem trabalhado para ser considerado válido, pode, em seguida, ser apresentado para os novos membros como o modo correto de perceber, pensar e sentir em relação a esses problemas. De acordo com o 
autor os níveis de análise cultural são compostos por artefatos, crenças e valores expostos e suposições básicas, conforme Figura 1.

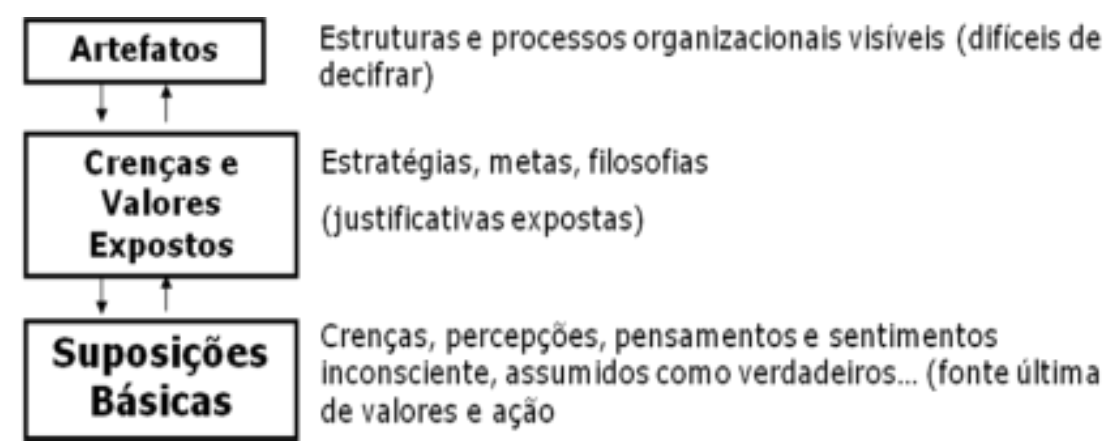

Figura 1 - Níveis da Cultura. Schein (1992)

Já, para Hofstede (2001), a cultura se apresenta-se em camadas, como uma "cebola", e para a sua real compreensão, deve-se descascá-la, e analisar uma camada de cada vez. Da mais externa para a mais interna estão presentes:

a) símbolos: palavras, objetos e gestos de significado consagrado. No nível da cultura nacional, os símbolos correspondem à linguagem e no nível da cultura organizacional correspondem a gírias, maneiras de trajar e posições de status;

b) heróis: são pessoas imaginárias ou reais, vivas ou mortas, indicadas como modelos de comportamento;

c) ritos: são atividades tecnicamente dispensáveis, mas socialmente significativas no contexto de determinada cultura; d) valores: constituem o nível mais profundo de uma cultura. São os sentimentos amplos, muitas vezes inconscientes e indiscutíveis (premissas básicas), envolvendo categorias éticas, estéticas, ideológicas; tais categorias são compartilhadas pelos integrantes de um grupo ou por seus líderes.

Hofstede (2001), considera os símbolos, os heróis e os ritos como "práticas" por serem visualizados externamente, conforme Figura 2. O significado destas práticas será obtido por meio do entendimento das interpretações designadas a elas pelo grupo. Já, os valores localizam-se no núcleo "duro" da cultura e se referem a "tendência para se preferir certo estado de coisas em face de outro. (HOFSTEDE, 2001, p.23). 


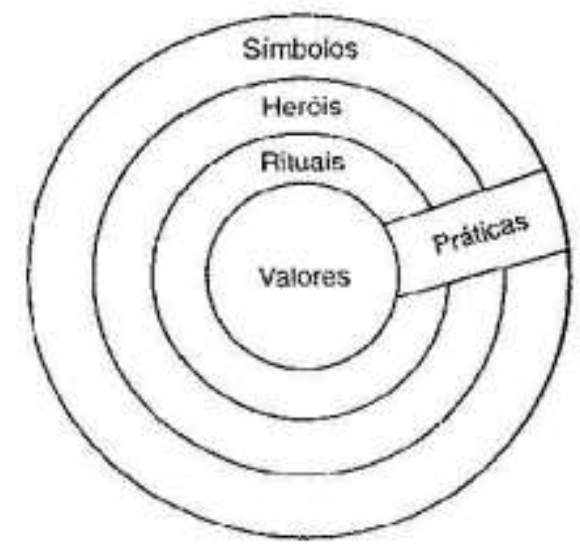

Figura 2 - Elementos da Cultura. Hosfstede (2001)

Segundo Alvesson (2002), os modelos

Já, para Alvesson (2002), a cultura envolveria as experiências, significados, valores e compreensões associados ao meio ambiente que são aprendidos e compartilhados, e que se expressam, se reproduzem e são comunicados, pelo menos parcialmente, de forma simbólica.

Para o autor, as definições de cultura revelam pouco sobre os intrincados problemas teóricos conceituais que lhes são subjacentes. Além disso, uma definição pode se adotada por autores de diferentes perspectivas. No entanto algumas pressuposições do fenômeno permanecem nos conceitos de diferentes visões: a cultura organizacional se relaciona com a história e a tradição; possui alguma profundidade; é difícil de se decifrar e explicar, mas deve ser interpretada; é por natureza coletiva, compartilhada e ideacional; refere-se a valores, crenças, conhecimentos e outro aspectos mais profundos; é holística e subjetiva ao invés de racional e analítica. teóricos sobre as diversas formas de manifestações culturais apresentam algumas semelhanças, mas também divergências conceituais que irão influenciar nas pesquisas.

\subsection{Abordagens Metodológicas no Estudo de Cultura Organizacional}

De acordo com Reichers e Schneider (1990), a introdução do termo cultura na psicologia organizacional coincidiu com o interesse por metodologias qualitativas, visando a interpretação dos fenômenos organizacionais como singulares e idiossincráticos e não como generalizáveis, como se acredita devido aos estudos de clima organizacional que utilizavam o método quantitativo.

Para Rousseau (1990), muitos estudiosos de cultura organizacional defendem o uso do método qualitativo, visto que para estes a cultura é um fenômeno socialmente construído que só poderá ser 
compreendido por meio de uma análise interpretativa.

Segundo Schein (1992), estudos culturais se baseiam na compreensão dos pressupostos básicos compartilhados, definidores da cultura, que são elementos profundos e inacessíveis. Assim sendo, os métodos qualitativos seriam mais eficazes para se identificar estes elementos inacessíveis, profundos e inconscientes.

Em contrapartida, segundo Rousseau (1990), os autores que focam na análise dos elementos intermediários da cultura, como valores esposados referentes às ações e resultados organizacionais desejados ou normas sobre como os membros da organização devem se comportar e interagir, são adeptos do método quantitativo.

Para o autor, o emprego deste método possibilita o envolvimento de um número maior de membros, de diferentes posições hierárquicas e pertencentes a diferentes subunidades da organização, bem como a validação consensual das respostas fornecidas. Assim, as múltiplas perspectivas subjacentes à organização podem ser melhor avaliadas e comparadas em seus aspectos intra e interorganizacionais.

Estudos fidedignos positivistas sobre cultura foram desenvolvidos com o uso de métodos quantitativos.

Hofstede (2001), realizou um estudo com abordagem quantitativa sobre as diferenças culturais existentes em vários países, com o intuito de analisar a importância da cultura nacional na forma de se administrar. Em seu estudo, em 50 países e três regiões (África ocidental, África oriental e países de língua árabes), o autor identificou diferenças significativas entre os comportamentos e atitudes dos funcionários das 53 subsidiárias da IBM, empresa foco do estudo. $\mathrm{O}$ autor concluiu que a cultura nacional influenciava nas relações dos indivíduos mantidas com o trabalho

Denilson e Mishra (1995), desenvolveram um modelo de cultura organizacional e eficácia com base em quatro traços das culturas organizacionais. Primeiramente, estudos de caso qualitativos de cinco empresas foram utilizados para identificar as características e a natureza da ligação destes traços com a eficácia. Posteriormente, um estudo quantitativo forneceu uma análise exploratória das percepções dos executivos destas quatro características e sua relação com medidas subjetivas e objetivas de eficácia em uma amostra de 764 organizações.

A pesquisa realizada por Gillespie el al (1995), apresentou o impacto que traços da cultura organizacional têm na satisfação do cliente. Foram examinadas 32 empresas de materiais de construção e 148 concessionárias de automóveis. Neste estudo, os traços da cultura organizacional, relacionaram-se significativamente com a satisfação dos clientes em ambas as amostras. Estes 
resultados sugeriram que a cultura de uma organização se relaciona substancialmente com a satisfação de seus clientes, já que a relativa magnitude de cada traço pode variar entre as empresas ou indústrias.

Cameron e Quin (1999), desenvolveram um Instrumento de Avaliação da Cultura Organizacional (OCAI), utilizado para diagnosticar a cultura da organização. De acordo com os autores este instrumento já foi utilizado por mais de mil organizações e demonstrou predizer o desempenho organizacional. Sua intenção é ajudar a identificar a cultura atual da organização, além de ajudar a identificar a cultura que os membros da organização acham que deveria ser desenvolvida para atender a futura demanda do meio e os desafios a serem encarados pela companhia.

É importante ressaltar que a perspectiva epistemológica do pesquisador, bem como os elementos culturais de seu estudo estão relacionados ao tipo de metodologia utilizada na investigação do constructo.

Segundo Rosseau (1990), em relação a perspectiva epistemológica, os que possuem uma visão positivista/objetivista da realidade pregam o uso de métodos quantitativos por considerarem a estrutura concreta e mensurável, por ser compreendida em termos unívocos, bem definidos e generalizáveis. Os que seguem uma visão subjetivista/interpretativa propõem o uso de métodos qualitativos pelo fato de visualizarem os fenômenos culturais como construções sociais únicas e particulares, que exigem avaliações flexíveis, interativas e específicas para cada contexto.

Rosseau (1990), afirma que a dicotomia entre metodologias quantitativas e qualitativas vem sendo gradativamente substituída pela tentativa de conciliação destas metodologias, o que resultaria na proposta de adoção de métodos múltiplos. A análise quantitativa de dados qualitativos permitiria uma exploração mais rigorosa de atributos que se mostram inadequados a uma avaliação por meio de instrumentos personalizados. Já a análise interpretativa de dados coletados por questionários possibilitaria uma maior compreensão dos padrões culturais.

Segundo Hunt (1994), o termo positivista na literatura gerencial tem sido usado por conveniência. A ciência tem um status especial não porque é um caminho seguro de produção de verdade evitando a falsidade, mas porque é uma prática comum de uma comunidade com um marco rígido com a moralidade, produzindo verdades, trabalhos confiáveis. A ciência não é um aglomerado de materiais e práticas cognitivas, mas sim uma conquista moral. $\mathrm{O}$ preço pago pela falsa retórica histórica é a potencial destruição da confiança entre acadêmicos e seu público. Ainda, de acordo com o autor, deveríamos reconhecer a complementaridade 
dos métodos quantitativos e qualitativos, de reconhecer a nossa responsabilidade por produzir trabalhos fidedignos, independente de seu método, nos abstendo do relativismo e do subjetivismo.

\section{CONSIDERAÇÕES FINAIS}

O estudo realizado permitiu identificar que a abordagem epistemológica e metodológica predominante nos estudos da cultura organizacional, respectivamente, é a interpretacionista e a qualitativa, provavelmente devido ao fato que o termo cultura foi introduzido na psicologia organizacional no momento em que surgiu um maior interesse por metodologias qualitativas, visando à interpretação dos fenômenos organizacionais como singulares e idiossincráticos e não como generalizáveis.

No entanto, observou-se que estudos positivistas fidedignos com abordagem quantitativa foram realizados e ofereceram consideráveis contribuições ao campo de pesquisa, principalmente por permitirem a análise de uma maior amostra de indivíduos, pertencentes a diferentes extratos.

O tipo de abordagem epistemológica e metodológica irá depender das manifestações culturais escolhidas para estudo. Identificouse que as premissas básicas da cultura mais profundas e inacessíveis como valores e crenças, deverão ser estudadas conforme uma perspectiva interpretacionista-qualitativa, visto que estas premissas poderiam ser compreendidas apenas por meio da interpretação do comportamento do indivíduo. Já, as manifestações localizadas nos elementos mais externos da cultura que se referem às ações e normas sobre como os membros da organização devem se comportar ou agir, ou como Hofstede chamaria as "práticas", poderão ser analisados segundo uma perspectiva positivista-quantitativa.

Ambas abordagens oferecem contribuições para os estudos da cultura organizacional, visto que a cultura, conforme podemos observar segundo as afirmações dos principais teóricos da área, não seria formada apenas de valores, crenças e outros aspectos profundos, mas também de elementos externos, os produtos "visíveis" do grupo, como seu ambiente físico, linguagem, rituais, etc. O paradigma positivista possibilita analisar estes traços culturais externos e o interpretacionista as manifestações que expressam a consciência humana.

Ainda, quanto às abordagens metodológicas, a adoção de métodos múltiplos poderia fazer progressos nas pesquisas sobre cultura organizacional. No estudo realizado por Denilson e Mishra (1995), os métodos qualitativo e quantitativo foram de suma importância para uma compreensão mais ampla da relação entre eficácia e cultura organizacional. Um acompanhamento qualitativo iria claramente 
reforçar as conclusões que poderíamos obter dos dados quantitativos.

Quanto às abordagens teóricas, diferentes manifestações culturais são enfatizadas, o que pode influenciar nas pesquisas. Pressuposições de que a cultura organizacional se relaciona com a história e a tradição, que é difícil de ser decifrada e explicada mas deve ser interpretada, é por natureza compartilhada e ideacional referindo-se a valores, crenças e outros conhecimentos mais profundos, estão presentes nas visões dos diferentes teóricos.

Este cenário confirma o que Reichers e Schneider (1990) afirmaram, que esse campo de conhecimento, embora vasto e promissor, ressente-se ainda de maturidade e integração teórica.

Enfim, deve-se reconhecer a complementaridade das diferentes abordagens epistemológicas e metodológicas, visando produzir trabalhos fidedignos que possam contribuir para uma maior compreensão e elucidação dos diferentes elementos da cultura, bem como a influência destes elementos na gestão organizacional.

\section{REFERÊNCIAS}

ALVESSON, Mats. Understanding organizational culture. London: SAGE Publications, 2002.

CAMERON, K. S.; QUINN, R. E.

Diagnosing and changing organizational culture. Massachusetts: Addison-Wesley, 1999.

CAVEDON, N.R. O Método etnográfico em estudos sobre cultura organizacional: implicações positivas e negativas. XXIII ENANPAD, Foz do Iguaçu, 1999
DENZIN, N. K.; LINCOLN, Y. S. (ed.) Handbook of qualitative research.

Thousand Oaks, CA: Sage, 1994. p. 105-117.

DENISON, Daniel; MISHRA, Aneil. K. Toward theory of organizational culture and effectiveness. Organization Science. V6, n2, p. 204-223. March-April, 1995.

DONALDSON, L. Teoria Organizacional como uma ciência positive. In: TSOUKAS, H.; KNUDSEN, C. (ed.) The Oxford Handbook of organization theory. Oxford: Oxford University Press, 2003. p 63 a 87.

GILLESPIE, Michael A. et al. Linking organizational culture and customer satisfaction: Results from two companies in different industries. European Journal of Work and Organizational Psychology, v.17, n.1, p.112-132, 2008

\section{HOFSTEDE, Geert. Culturas e}

organizações: compreender a nossa programação mental. Lisboa: Edições Silabo, 2001.

HUNT, Shelby D. On the Rhetoric of Qualitative Methods: Toward Historically Informed Argumentation in Management Inquiry. SAGE Publications, 1994.

MORGAN, G.; SMIRCICH, L. The case for qualitative research. Academy of Management Review, 1980.

PÉPIN, Normand. "Cultura de empresa. Nascimento, alcance e limites de um conceito". In: Mosaico - Revista de Ciências Sociais, v. 1, n. 1. Vitória: UFES-CEG, 1999.

REICHERS, A. E. SCHNEIDER, B. Climate and Culture: The case for multiple methods In: Schneider, B. (Org.), Organizational Climate and Culture. San Francisco: JosseyBass, 1990. 
REMENYI, D. WILLIAMS, B. MONEY, A.

SWARTZ, E. Doing research in business

and management: an introduction to

process an method. London: Sage

Publications, 1998.

ROUSSEAU, D M. Assessing Organizational

Culture: The Case for Multiple Methods. In:

Schneider, B. (Org.), Organizational

Climate and Culture. San Francisco: Jossey-

Bass, 1990.

SCHEIN, Edgar H. Organizational culture

and leadership. San Francisco, CA: Sage,

1992.

TROMPENAARS, Fons. Nas ondas da

cultura: como entender a diversidade cultural

nos negócios. São Paulo: Educador, 1994.

VIEIRA, M. M. F.; CALDAS, M. P.

Teoria crítica e pós-modernismo:

Principais alternativas à hegemonia

funcionalista. Revista de Administração de

Empresas. São Paulo, v.46, n.1, jan/mar,

2006. 